Artículo de investigación

Cómo citar: Guerrero, S. (2019).

La minería como dinamizadora

de conflictos socioculturales en

el municipio de Lloró, Chocó,

Colombia, Polisemia, 15(27), 39-57.

http://doi.org/10.26620/uniminuto.

polisemia.15.27.2019.39-57

ISSN: $1900-4648$

elSSN: $2590-8189$

Editorial: Corporación Universitaria Minuto de Dios - UNIMINUTO

Recibido: 4 marzo 2019

Aceptado: 6 abril 2019

Publicado:15 mayo 2019

\title{
La minería como dinamizadora de conflictos socioculturales en el municipio de Lloró, Chocó, Colombia
}

\section{Mining as a driver of socio-cultural conflicts in the municipality of Lloró, Chocó, Colombia}

\section{A exploração mineira como motor do conflito sócio-cultural no município de Lloró, Chocó, Colômbia}

\section{Resumen}

Esta investigación tiene como objetivo principal analizar la relación entre los conflictos socioculturales en el municipio de Lloró, Chocó, Colombia y la minería aluvial en los últimos 10 años (2007-2017). A partir de ello se encuentra que hay una correlación entre la configuración de un modelo minero aurífero con diferentes actores que incrementó los problemas familiares y comunitarios.

Para esta investigación se realizaron entrevistas semi-estructurales con líderes comunitarios, organizaciones comunitarias (Consejo comunitario) y funcionarios de la Alcaldía de Lloró, quienes proporcionaron información relevante y contundente para afirmar que las conflictos en el municipio obedecen al aumento de la actividad minera, que inició en 2008 con la entrada de aproximadamente 37 retroexcavadoras de propiedad de personas foráneas y con el permiso de la Alcaldía Municipal, consejos comunitarios y familias dueñas de los predios. Aunque para el año 2012 esta cifra se baja a 25 retroexcavadoras se agudizan los conflictos con la llegada de bandas criminales. En lo corrido del 2016 en el municipio existían aproximadamente 10 dragones $^{1}$ y 2 para el año 2017.

1 Draga con clasificador y concentrador sobre plataforma flotante de mediano tamaño que succiona tierra de la profundidad de los ríos. 
Este estudio muestra que al pasar de un modelo socio-económico agrícola a un modelo socio-económico minero, dirigido por foráneos nacionales y extranjeros, se generan rupturas sociales y culturales, y se provoca un cambio sustancial en el relacionamiento de los ciudadanos del municipio, lo que demuestra que existe una estrecha relación entre la cultura, el comportamiento social y la actividad económica.

Los principales aspectos donde se evidencia los cambios son el sociocultural con la música, la dieta alimentaria, el lenguaje, el vestuario, el medio ambiente, el cambio en el comportamiento socio-cultural de los jóvenes y el inicio de homicidios; en el aspecto familiar se identificaron problemas en los límites o linderos entre las familias, problemas en la tenencia o propiedad de la tierra (las familias no llegan a un acuerdo para alquilar o vender el terreno para el ejercicio de la minería, las familias pelean la propiedad de las tierras, las familias no llegan a un acuerdo en la redistribución de las ganancias); y en el aspecto comunitario problemas en los límites y linderos entre comunidades y entre municipios.

Palabras clave: minería, conflicto, sociocultural, foráneos, intrafamiliar, interfamiliar, comunidad.

\begin{abstract}
The main objective of this research is to present how the socio-cultural conflicts in the Colombian municipality of Lloró, located in Chocó department have been invigorated in the last 10 years $(2007-2017)$ by the alluvial mining, finding a correlation between the setting of an auric mining model with different actors that increased the familiar and community problems.

For the purpose of this investigation, semi-structured interviews were conducted with community leaders, community organizations (Community Council) and civil servants from the municipal government who provided relevant and conclusive information to affirm that the conflicts in the municipality are related to the increase of the mining activity which began in 2008 with the entry of approximately 37 backhoes into the hands of outsiders with the permission of both the Mayor's Office, community councils and families who own the properties; In 2012 Approximately, the number of backhoes was reduced to 25 and the conflict got worse with the arrival of criminal groups; so far in 2016 there are approximately 10 dragons in the municipality in 2017 they are revitalize by the presence and operation of two "dragones".

This study shows that when moving from an agricultural socio-economic model to a directly mining socio-economic model in the hands of foreign nationals and foreigners, they generate social and cultural ruptures, causing a substantial change in the relationship of the citizens of the municipality; making it clear that whether there is a close relationship between culture, social behavior and economic activity.
\end{abstract}


The main aspects where changes were noted were: the socio-cultural aspect, specifically in music, diet, language, clothing, environment, change in the socio-cultural behavior of young people, initiation of homicides; In the family aspect, problems were identified in the limits or boundaries between the families. Problems in the possession or ownership of the land, (the families do not reach an agreement to rent or sell the land for the mining activity, the families fight land ownership, families do not agree on redistribution of profits). In the community aspect, problems in the limits and boundaries between communities and between municipalities.

Keywords : mining, conflict, sociocultural, foreigners, intra-familiar, inter-familiar, community.

\section{Resumo}

O principal objetivo desta pesquisa é analisar a relação entre os conflitos socioculturais no município de Lloró, Chocó, Colômbia e a mineração aluvial nos últimos 10 anos (2007-2017). A partir disto, constata-se que existe uma correlação entre a configuração de um modelo de mineração de ouro com diferentes atores que aumentaram os problemas familiares e comunitários.

Para esta pesquisa, foram realizadas entrevistas semi-estruturais com líderes comunitários, organizaçóes comunitárias (Conselho Comunitário) efuncionários da Prefeitura Municipal de Lloró, que forneceram informaçóes relevantes e convincentes para afirmar que os conflitos no município se devem ao aumento da atividade mineira, que começou em 2008 com a entrada de aproximadamente 37 retroescavadeiras de propriedade de estrangeiros e com a permissão da Prefeitura Municipal, conselhos comunitários e famílias proprietárias da terra. Embora em 2012 este número tenha caído para 25 retroescavadeiras, os conflitos se agravaram com a chegada de quadrilhas criminosas. Até agora, em 2016, no município havia aproximadamente 10 dragóes e 2 para o ano 2017.

Este estudo mostra que quando se passa de um modelo sócio-econômico agrícola para um modelo sócio-econômico mineiro, liderado por estrangeiros e estrangeiros, são geradas rupturas sociais e culturais, e uma mudança substancial é causada na relação dos cidadãos do município, o que mostra que existe uma relação estreita entre cultura, comportamento social e atividade econômica.

Os principais aspectos onde as mudanças são evidenciadas são o sociocultural com música, dieta alimentar, idioma, vestuário, meio ambiente, a mudança no comportamento sociocultural dos jovens e o início dos homicídios; No aspecto familiar, foram identificados problemas nos limites ou limites entre famílias, problemas na posse ou propriedade da terra (as famílias não chegam a um acordo para alugar ou vender terra para mineração, as famílias lutam pela posse da terra, as famílias não chegam a um acordo sobre a redistribuição dos lucros); e no aspecto comunitário, problemas nos limites e limites entre comunidades e entre municípios.

Palavras-chave: mineração, conflito, sociocultural, forasteiros, intra-família, inter-família, comunidade. 


\section{Introducción}

El presente artículo visibiliza la situación de los conflictos socioculturales que se han presentado en el municipio de Lloró, Chocó en Colombia, como consecuencia del incremento de la actividad minera aurífera aluvial e ilegal en manos de actores externos, sin ningún control por parte de las autoridades competentes. Lloró cuenta con una población aproximada para 2016 de 11.284 habitantes (DANE, 2016) de los cuales el $26.1 \%$ pertenecen a comunidades indígenas y un $73.6 \%$ pertenecientes a comunidades negras o afrodescendientes. Antes del año 2007 la principal actividad económica era la agricultura, se producía caña de azúcar, piña, borojó, plátano, banano, primitivos y yuca, entre otros productos de la canasta familiar autóctonos de la región; igualmente se ejercía la pesca, la ganadería y la minería de forma tradicional; sin embargo en los últimos 10 años la actividad económica predominante ha sido la minería aurífera mecanizada con marcada presencia en el periodo de 2008 a 2011, con la presencia de aproximadamente 37 retroexcavadoras (Ayala, 2016), hay quienes creen que el municipio llegó a tener "entre 60 y 70 entables mineros" (La otra Colombia, 2017).

Esta situación generó un cambio en la actividad económica de las familias, se pasó de la agricultura a la actividad minera, así como un "retorno de personas oriundas del municipio que se encontraban en otros departamentos" (Segalla, 2017), motivados por la llegada de foráneos nacionales y extranjeros que se establecieron en el municipio para ejercer la actividad minera ilegal, así mismo esta actividad trajo consigo mayor presencia de grupos al margen de la ley y bandas criminales, lo que provocó una trasformación socio-cultural que afectó la seguridad alimentaria de sus habitantes, la seguridad de los ciudadanos y el medio ambiente. De igual manera provocó fragmentación de los lazos familiares y comunitarios del municipio. Este último aspecto es en el que se enmarca explícitamente esta investigación.

Son muchos los estudios sobre el impacto que genera la actividad minera en los recursos naturales, el medio ambiente, la relación con los grupos al margen de la ley y el conflicto armado, la distribución de los recursos y el impacto en la calidad de vida de las poblaciones. Entre esos estudios se pueden mencionar las investigaciones que ha hecho la Contraloría General de la Nación, la Universidad Militar Nueva Granada, los estudios de la Fundación Ideas para la Paz, el Cinep, el Programa por la Paz, entre otros; pero muy poco sobre las causas y efectos que tiene en las relaciones familiares y los lazos comunitarios, por lo que este trabajo pretende evidenciar el daño social y cultural que esta actividad minera aurífera aluvial genera en los territorios a manos de actores externos.

La minería aurífera aluvial, sobre todo la ilegal en Colombia, se perfila como uno de los temas en la agenda de Gobierno de los próximos años, no solo por el impacto que puede tener en relación con el conflicto armado interno, sino en general por el impacto en la economía nacional y las relaciones sociales colombianas (Moncada, 2012). Así mismo, la Contraloría General de la Nación en su estudio La explotación ilícita de recursos minerales en Colombia, casos Valle del Cauca (Río Dagua) - Chocó 
(Rio San Juan). Efectos sociales y ambientales (2016), similares en contexto y tipo de actividad minera aurífera aluvial realizada, alude que este tipo de actividad usurpa la propiedad privada o colectiva de los territorios, lo que afecta los recursos naturales, genera problemas de salubridad pública, seguridad alimentaria, desplazamiento forzoso y otras afectaciones de orden social (Torres et al., 2016).

Estas afirmaciones son relevantes para visibilizar las problemáticas socio-culturales que afectan el relacionamiento familiar, interfamiliar y comunitario, que van desde los patrones culturales de los ciudadanos, al parecer por la llegada de foráneos nacionales y extranjeros dedicados a la actividad minera aurífera aluvial con patrones y costumbres diferentes, así como cambios drásticos en el relacionamiento familiar debido a los conflictos intrafamiliares, causados por la dificultad para llegar a un acuerdo en alquilar o vender el terreno para el ejercicio de la minería o en la redistribución de las ganancias al interior de las mismas, lo que los lleva a utilizar la violencia verbal o física para solucionar los problemas. También acuden a la Inspección de Policía municipal como último y único medio formal de resolución de conflictos. Las causas de los conflictos interfamiliares se enmarcan en el tema de los límites o linderos, así como la tenencia de la propiedad. En lo comunitario obedece a temas de linderos entre corregimientos y veredas, incluso problemas de límites entre municipios.

Sumado a todas estas afectaciones, en el municipio de Lloró aumentó la presencia de grupos al margen de la ley vinculados a la actividad minera, quienes reforzaban la dinámica mediante la coerción de los ciudadanos, igualmente y según noticias del periódico El Tiempo "alrededor del oro hay una cadena criminal de muchas cosas. De la maquinaria, del mismo oro, del comprador, de los químicos que se utilizan. Hay prostitución, maltrato infantil, desplazamientos e invasión a la cultura de una región" (Zapata, 2014).

Pero la presencia de estos grupos se debe, según Conde (2012), a que las instituciones del departamento son débiles, lo que da un valor estratégico para los actores armados. Informes indican que en los últimos 10 años, el $80 \%$ de las violaciones de derechos humanos se produjeron en regiones minero-energéticas, principalmente en el Chocó. Este tipo de actividad ha sido combatida por el gobierno nacional, no solo por el impacto negativo que tiene sobre el medio ambiente y la sociedad, sino, porque se ha convertido en una fuente de financiación importante para los grupos al margen de la ley.

De acuerdo con la inspectora de policía, en el periodo 2008-2011, con la llegada de foráneos nacionales y extranjeros que ejercen la actividad minera, se iniciaron las denuncias por el tema de propiedad de territorios por parte de familias y personas de la comunidad (Ramos, 2016), y empezaron los problemas de seguridad alimentaria, pues ya no era fácil conseguir productos de la canasta familiar autóctonos del municipio, la contaminación de los ríos fue inminente inclusive generó algunas protestas en la comunidad, al mismo tiempo adolescentes y jóvenes empezaron a faltar a las jornadas académicas por irse a las actividades del barequeo en los entables mineros (Cuesta, C., 2017). 
Para el periodo de 2012-2015 los conflictos y violencia se agudizaron, por el establecimiento permanente, en el corregimiento de Boraudo, de bandas criminales y post paramilitares, sin ningún control de las autoridades, quienes no solo llegaron a controlar los entables mineros mediante el cobro de extorciones, sino que se establecieron acciones hacia la comunidad, como cobro de vacunas a comerciantes y a toda aquella persona que ellos consideraran (Cuesta, E., 2017).

Para el año 2016, los conflictos fueron dinamizados por dragones que generaron dos conflictos entre las familias, y para el año 2017 los conflictos o problemas se presentaron por los límites de veredas, corregimientos y municipios (Palacios, H. A. 2016).

\section{Proceso metodológico de la investigación}

Este estudio se realizó bajo un paradigma cualitativo mediante el cual se realizó una descripción e interpretación de la realidad socio-cultural del municipio bajo un enfoque etnográfico hermenéutico. La investigación se orientó hacia la descripción del estudio de caso que permita conocer las afectaciones y particularidades de la situación social y cultural de la población del municipio de Lloró por la configuración de este tipo de minería aurífera aluvial a manos de actores externos, sin control estatal y con el sometimiento de las comunidades; se tomó como unidad de análisis el municipio de Lloró con sus corregimientos y veradas, y como unidad de estudio solo la cabecera municipal, debido a los riesgos que esta investigación podría tener.

Para la obtención de información se realizaron entrevistas semiestructuradas a un muestreo aleatorio estratificado, con las instituciones, organizaciones y adultos mayores presentes en el municipio, instituciones educativas, Iglesia, comercio, el consejo comunitario de Lloró, padres de familia, concejales, jóvenes, líderes comunitarios y mineros artesanales del municipio. Dentro de estos grupos se trabajó con personas con las que se pudiera identificar de manera clara y objetiva los cambios y afectaciones dentro del municipio, Lloroseños que estuvieran viviendo en el municipio o personas que llevaran más de 10 años viviendo en él; personas que desde su ámbito tuvieran mayor liderazgo y reconocimiento en su gremio, con conocimiento sobre las dinámicas del municipio.

De igual manera se hizo revisión documental en bases de datos de revistas científicas, periódicos, algunos estudios de caso y entrevistas a personas clave, como los adultos mayores, el inspector de policía y la personería.

Las entrevistas fueron realizadas a once sectores dentro del municipio, como se muestra en la tabla 1. En el sector institucional específicamente en la Alcaldía Municipal, fue necesario entrevistar a los anteriores inspectores de policía, ya que no se encontró registros o archivos de años anteriores. Igualmente, en el sector educativo se trabajó con docentes de básica primaria de la Escuela Julio Figueroa Villa, y docentes de secundaria del Colegio Departamental Agrícola de Lloró. 
Tabla 1. Número de entrevistas realizadas

\begin{tabular}{l|c|c}
\hline \multicolumn{1}{c|}{$\begin{array}{c}\text { Gremio, entidad } \\
\text { u organización }\end{array}$} & Cantidad & $\begin{array}{c}\text { Número de } \\
\text { entrevistas }\end{array}$ \\
\hline Instituciones educativas & 2 & 7 \\
Comerciantes & 1 & 10 \\
COCOILLO & 1 & 2 \\
Padres/madres de familia & 1 & 10 \\
Inspección de Policía & 1 & 3 \\
Líderes comunitarios & 1 & 5 \\
Concejales & 1 & 2 \\
Jóvenes & 1 & 3 \\
Mineros artesanales & 1 & 1 \\
Iglesia & $\mathbf{1 1}$ & $\mathbf{4 8}$ \\
\hline Total & & \\
\hline
\end{tabular}

Fuente: Violencia contra líderes sociales (2018).

\section{Impactos socioculturales por minería en el municipio de Lloró}

Para esta investigación se ha tomado el concepto de cultura como la forma y la manera como un pueblo o una comunidad se desarrolla, es un tejido social que define las distintas formas y expresiones, por lo tanto las costumbres, las prácticas, la comida, las maneras de ser, los rituales, los vestidos, la música, los bailes y las normas de comportamiento son parte importante de una comunidad (Rish, 2005).

Históricamente la economía del municipio de Lloró se ha basado en la agricultura como actividad principal, seguido de la minería artesanal y la explotación de madera, lo que ha propiciado, cultural y socialmente, una estrecha relación entre sus habitantes y su medio ambiente.

Durante las entrevistas en el municipio de Lloró, se encontró que el 100 $\%$ de los entrevistados coinciden en que se notaron cambios sustanciales en la dinámica social y cultural del municipio, como causa del ejercicio y aumento de la actividad económica de la minería, lo que deja claro que existe una estrecha relación entre la cultura, el comportamiento social y la actividad económica. Los principales aspectos donde se evidenciaron los cambios socio-culturales fueron los siguientes: 


\section{Música}

Era muy similar a la escuchada en la capital del departamento del Chocó, había influencia de la música vallenata, que normalmente se escuchaba en épocas como la fiesta de la Virgen del Carmen y los fines de semana, así como la salsa y el reggaetón. Sin embargo, con la presencia de foráneos dedicados a la minería, la música se comenzó a escuchar cualquier día de la semana y a alto volumen, los géneros cambiaron, y lo que más se escuchaba eran los corridos o música norteña, especialmente en el periodos de 2008 a 2014. Los corridos son música originaria de México que culturalmente pretendió informar a la gente sobre la vida e historia de legendarios como Pancho Villa y Emiliano Zapata, sin embargo esta tuvo cambios sustanciales en épocas recientes; de hecho, respecto al narcotráfico y la cultura de la mafia pasan de llamarse corridos a narcocorridos (URCM, 2008).

Corridos que llevan mensajes incorrectos a la sociedad en torno a la ilegalidad y la violencia.

La música es un producto social y, a su vez, una poderosa generadora de valores, creencias, aspiraciones, sentidos y prácticas que trascienden el campo de los espacios socio-musicales, la relación entre este tipo de música y una sociedad descompuesta tiende a generar círculos de decadencia que claramente indican mayor violencia en el proceso de descomposición social que hoy se vive. (Ramírez, 2012, p. 181).

\section{Comida}

En este aspecto también se evidenciaron cambios, que si bien no afectaron definitivamente la nutrición de los habitantes, dificultaron la oferta y demanda de alimentos, ya que durante un buen tiempo en el municipio de Lloró los productos básicos de la agricultura escasearon debido a que sus habitantes se dedicaron a la actividad minera y dejaron de lado el tema del cultivo de alimentos y actividades como la pesca y la cacería, escaseó el pescado, el banano, el plátano, la piña, el limón, entre otros productos de fácil consecución, lo que obligó a los habitantes y comerciantes a traer la mayoría de los productos básicos desde la ciudad de Quibdó, especialmente en el periodo de 2008 a 2013.

\section{Lenguaje}

Este aspecto hace referencia a las expresiones y formas de comunicación violenta entre los jóvenes, producto de los cambios generados por la actividad económica de la minería, por ejemplo, algunos entrevistados creen que el tipo de música que se escuchó definió en gran medida el comportamiento corporal y oral de los jóvenes. Es muy común entre ellos, adoptar como propias, conversaciones acerca de la marihuana, la coca, el paramilitarismo, grupos de guerrillas, influenciados por la dinámica económica, la presencia de grupos al margen de la ley y bandas criminales, sus expresiones hacia los adultos mayores y autoridades cambiaron de manera drástica. En otras palabras se perdió el respeto para dirigirse a sus pares y demás miembros de la comunidad. 


\section{Vestuario}

Según personas entrevistadas se notó un cambio significativo en la forma y manera de vestir de los habitantes, especialmente de las personas que se relacionaban directamente con la actividad minera y en algunos jóvenes del pueblo, ya que aquellos mineros se convirtieron en imagen de admiración para los jóvenes, querían vestir con ruanas, ponchos, sombreros y botas; en el caso de las mujeres andaban un poco más ligeras de ropa, supuestamente para llamar la atención de los mineros.

\section{Mujeres}

Dentro de la nueva dinámica se alude que muchas jóvenes y adolescentes mantuvieron relaciones sentimentales con los mineros, quedaron en estado de embarazo y hoy son madres solteras sin respaldo económico, lo que genera conflictos en su relacionamiento familiar.

Igualmente se empezaron a desarrollar actividades de trabajo sexual, principalmente por mujeres foráneas. Ocho viviendas que eran casas de familia se convirtieron en chongos (lugares donde se venden bebidas alcohólicas y se ejerce la actividad sexual o prostitución), que han ido disminuyendo a medida que se ha reducido la actividad minera. En la actualidad sobreviven dos de estos establecimientos denominados chongos (datos suministrados por la Inspección de Policía de Lloró, 2016).

\section{Adolescentes y jóvenes}

De acuerdo con la pregunta sobre las afectaciones a la población joven, el $100 \%$ de los entrevistados señalaron que dichos cambios en el municipio han afectado a los jóvenes y adolescentes, afirman que ahora son más agresivos y conflictivos porque han adquirido costumbres ajenas. Se ve un aumento en el "consumo de sustancias psicoactivas (alcohol, marihuana, perica) aprendido de foráneos (nacionales e internacionales) que ejercen la actividad minera. Se estima que un porcentaje alto de jóvenes ha consumido o consume dichas sustancias" (Martínez, 2016); esto de acuerdo con la información suministrada por un expendedor de marihuana. Además, muchos dejaron sus actividades académicas por trabajar en las minas, pero con la salida de estos entables del municipio se han dedicado a realizar actividades delictivas como el hurto a los entables mineros que quedan, hurto a viviendas, venta de sustancias psicoactivas y a delincuencia común, entre otras actividades delictivas.

Los adolescentes y jóvenes se enfrentaron a nuevas dinámicas asociadas con esta actividad, que si bien se ha convertido en una forma de empleo para ellos, también fue el medio para el consumo de sustancias alucinógenas que agudizan la agresividad asociada a las cualidades propias en los cambios de la adolescencia y juventud, etapa de difícil manejo para los núcleos familiares, "así mismo al contar con recursos constantes experimentan un tema de poder y control sobre el otro, notándose actitudes de agresividad e irrespeto ante la familia, vecinos y ciudadanos en general" (Guerrero, 2016). 


\section{Ambiente}

En el tema ambiental, para la población ha sido muy notorio los efectos negativos de la minería en las fuentes hídricas (río Andagueda y río Atrato), de gran importancia para sus habitantes, estos han sido afectados por contaminación de mercurio, por la sedimentación de los ríos y por el cambio en el cauce, además se han dañado las orillas de los ríos, lo que dificulta el acceso e impide el relacionamiento de solidaridad, amistad, respeto de la comunidad que se dinamiza en ellos.

Durante la época de 2008 a 2015 se presentaron dificultades en el ámbito alimentario, ya que no hubo subienda de pescado y los animales de caza se habían alejado por la contaminación (Córdoba, 2016), sumado a todo esto el municipio no cuenta con los servicios básicos como aseo, alcantarillado y agua potable, por tanto las aguas lluvias y sus ríos se convierten en el principal medio de abastecimiento de dichas necesidades. El río se convierte en el principal medio donde se reconfiguran y dinamizan las relaciones, personales, sociales y culturales a raíz de las diferentes actividades del hogar (lavado de ropas, platos, medio de integración y paseos). Sin embargo como afirma Yasno (2014) "el uso desaforado de insumos químicos como el cianuro y el mercurio, en el caso de la minería de oro, han traído nefastas consecuencias para los ecosistemas, con un agravio especial para los recursos hídricos" (p. 6), igualmente la Revista Semana en su informe El horror y la sangre del oro, referencia que

(...) unos de los ríos con mayor contaminación en el Chocó son el río Atrato y el Andagueda (...), además de que sus cauces fueron desviados por la intervención de los complejos de la minería criminal y que estos son los ríos que suministran agua de consumo a los humildes habitantes tradicionales del departamento, son fuente de pesca y donde además se bañan y lavan la ropa (Manga, 2015).

Esto impide su uso y rompe con valores como el compañerismo, la solidaridad, ayuda mutua entre otros aspectos culturales que eran dinamizados por el uso de este medio.

\section{Presencia de grupos al margen de la ley y homicidios}

Con el aumento de la actividad minera en el periodo de 2008-2011, se generó un crecimiento de grupos al margen de la ley, que se disputaban el control de esta actividad. Para el periodo 2012- 2015 se instalaron en el municipio grupos post paramilitares o bandas criminales (Bacrim), y en el corregimiento de Boraudo se instalaron sin ningún control de las autoridades competentes. Con la presencia de estos grupos se incrementaron los problemas sociales de la comunidad. Con ellos llegaron homicidios de personas que ejercían esta actividad, extorsiones a los entables mineros y a los comerciantes, intimidación a la comunidad y sus líderes, e involucramiento de jóvenes en actividades delincuenciales. Se cambiaron las costumbres de relacionamiento entre habitantes de la comunidad y esto llevó a que la comunidad comenzara a cerrar sus viviendas y negocios más temprano. También provocó poca participación de las actividades comunitarias y miedo generalizado. 
Según personas entrevistadas, los casos de homicidios de personas foráneas y nativos en el municipio (Ver figura 1), guardan relación con el ejercicio de la actividad minera en los últimos años. De 2012 a 2016 ocurrieron aproximadamente nueve homicidios, el caso más emblemático fue el homicidio del señor Ezequiel Hinestroza, oriundo del municipio de Lloró.

Figura 1. Homicidios en Lloró como consecuencia de la actividad minera.

¿Sabe si se han presentado homicidios por minería en los últimos años en Lloró?

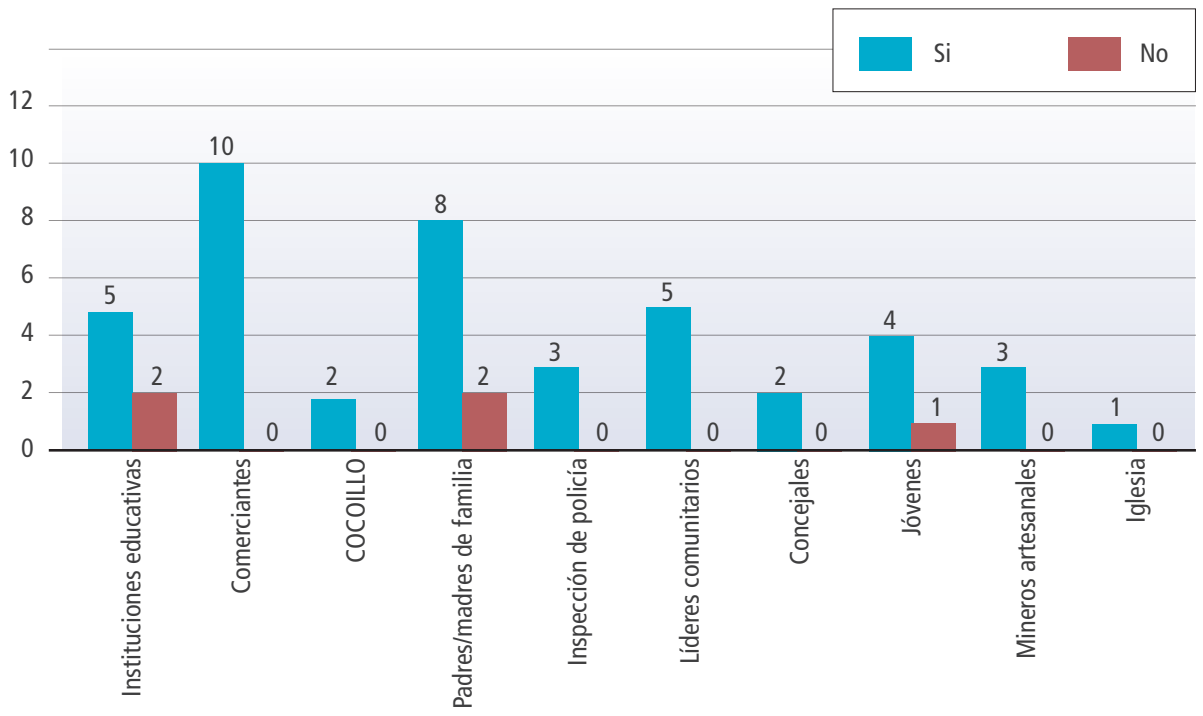

Fuente: Centro de Investigaciones y Estudios Sociales - CEIS (2013)

De acuerdo con la figura anterior, el $90 \%$ de los entrevistados manifestaron saber de homicidios que se habían presentado en el municipio, relacionados con la actividad minera, es decir de personas que trabajan en los entables mineros. Mientras que un $10 \%$ manifestaron no haber escuchado de homicidios relacionados con la actividad minera en el municipio de Lloró. Es importante resaltar que los tres inspectores de policía, el párroco del pueblo, los líderes comunitarios, comerciantes, concejales y COCOILLO, confirmaron que sí se presentaron dichos homicidios.

\section{Impacto intra e interfamiliares y comunitarios por minería en el municipio de Lloró}

En cuanto a los impactos de manera específica en el aspecto intra e interfamiliar, según entrevistas con los diferentes inspectores de policía, entre 2008 y 2011 se presentaron aproximadamente 31 casos de denuncias entre familias, por problemas relacionados con la actividad minera; de 2012 a 
2015 se presentaron 20 casos de denuncias; en lo corrido del año 2016 se han denunciado dos casos entre las familias. Se hace la salvedad que muchos de los denunciados y los denunciantes son repetitivos, para un total de 22 casos en vigilancia por la Inspección de Policía (Palacios, H. A., 2016), y para el año 2017 existieron cuatro conflictos entre las comunidades (ver figura 2).

Figura 2. Denuncias y entables mineros por periodos o fechas.

Denuncias familiares/comunitarios y numero de entables mineros por periodos o fechas.

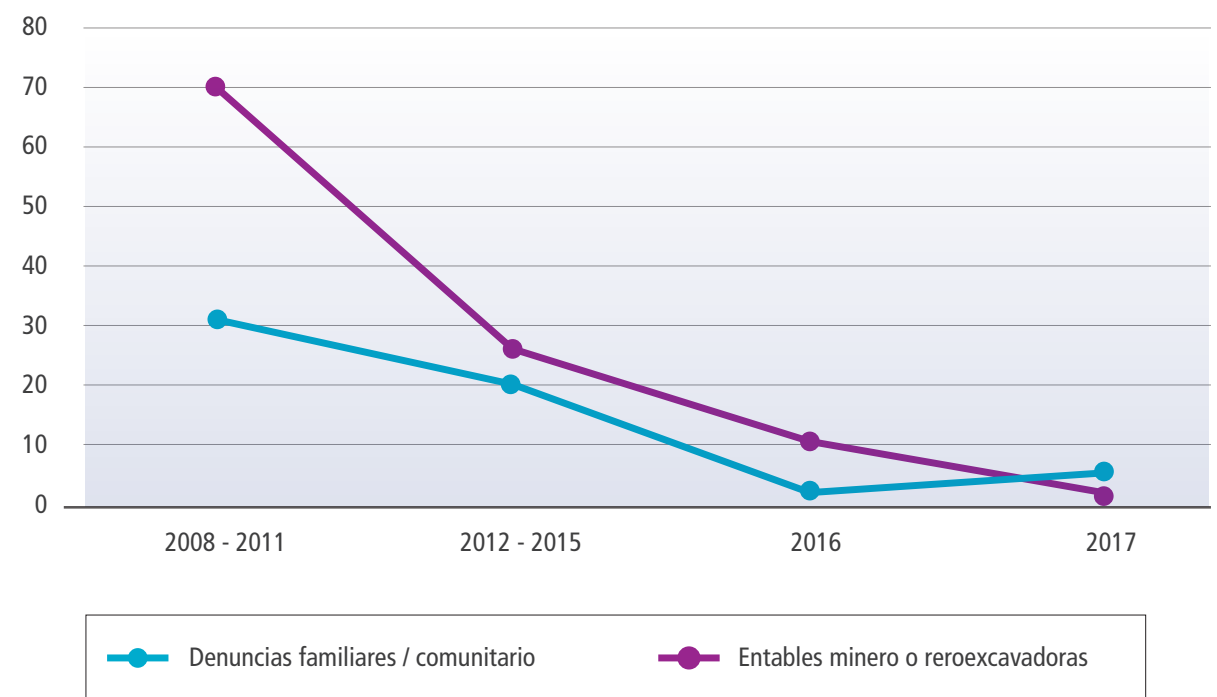

De acuerdo con la figura anterior se puede decir que la disminución en las denuncias por parte de las familias ante la Inspección de Policía, obedece a la disminución del número de los entables mineros o retroexcavadoras, es decir que para el periodo 2008-2011, por existir mayor presencia de máquinas ejerciendo la actividad minera se presentaron más casos de denuncias entre las familias, mientras que para el periodo 2012-2015 se presentó una disminución considerable de las maquinas o entables mineros, y los casos de denuncias igualmente disminuyeron. Teniendo en cuenta que la presencia marcada y sin ningún control de las bandas criminales restringió el actuar de la comunidad, para 2016 la actividad que se realizó sobre las fuentes hídricas y los conflictos familiares disminuyeron. En 2017 se presentaron cuatro conflictos a nivel comunitario, entre veredas, corregimiento y municipios.

Es importante resaltar que para 2016 se identificó el estado de las denuncias interpuestas por las familias durante el periodo 2012-2015, se encontró que hay 22 casos que están activos y en proceso de atención por la Inspección de Policía del municipio de Lloró (ver figura 3), y los conflictos entre municipios y veredas, que para 2017 eran 4, se encontraban en manos del Consejo Comunitario (Palacios, A. E., 2016) (ver figura 4). 
Figura 3. Denuncias inter e intra familiar.

Número de denuncias inter e intrafamiliar por minería

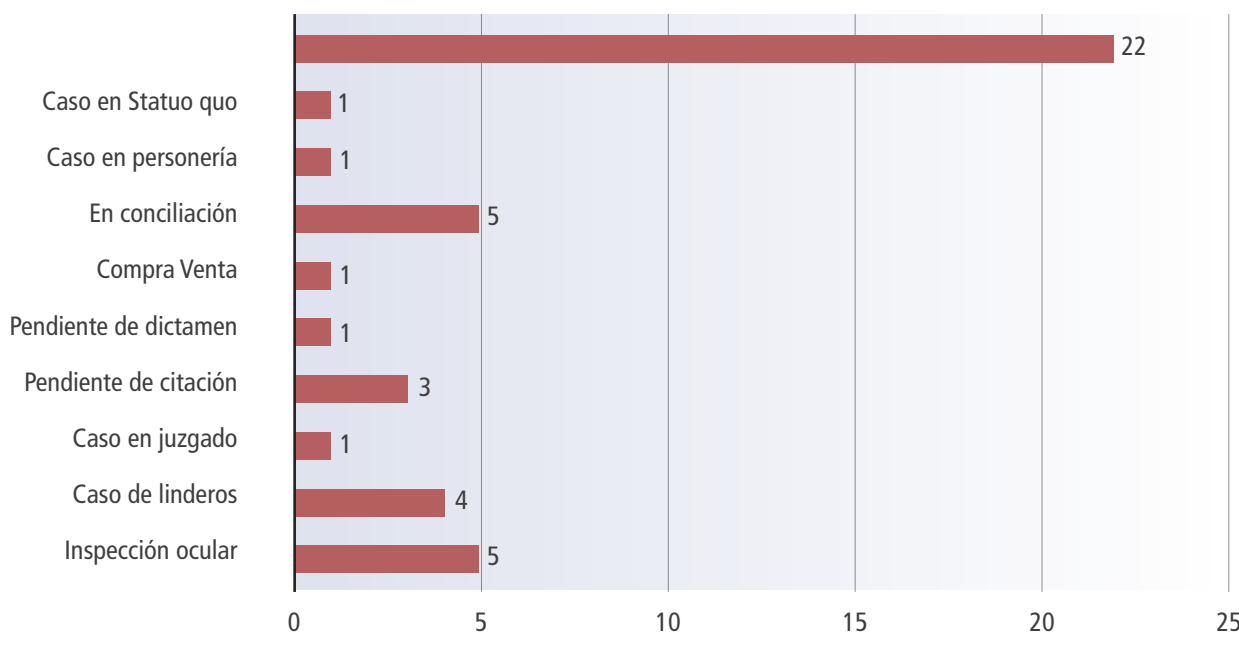

\section{Impacto intrafamiliar}

Los diferentes conflictos y denuncias presentadas por las familias se problematizan de acuerdo con las definiciones del concepto de familia, entendida como elemento natural y fundamental de la sociedad con derecho a la protección de la sociedad y del Estado. Los lazos principales que definen una familia son vínculos de afinidad, consanguinidad y lazos afectivos. También puede diferenciarse la familia según el grado de parentesco entre sus miembros, como nucleares, extensos, etc. (Enciclopedia Británica en español, 2009).

En el artículo 42 de la Constitución Política de Colombia, la familia es definida como el núcleo fundamental de la sociedad, la cual se constituye por vínculos naturales o jurídicos, por la decisión libre de un hombre y una mujer de contraer matrimonio, o por la voluntad responsable de conformarla. También es reconocida como la institución más importante y el núcleo de la sociedad, así, se encuentra protegida constitucional y legalmente (Vela, 2015).

Más allá de la definición, es claro que todo tipo de familia pasa por un proceso de adaptación, crisis y maduración, que puede poner en riesgo su consolidación. En el municipio de Lloró, de acuerdo con las entrevistas realizadas en los últimos años, se ha presentado una serie de conflictos intrafamiliares, que se evidencian en las denuncias interpuestas ante la Inspección de Policía, motivadas principalmente por el aumento de la actividad minera ejercida por foráneos en el municipio. Las causas más relevantes que generan problemas en los núcleos familiares son las siguientes:

- Las familias no llegan a un acuerdo para alquilar o vender un terreno para el ejercicio de la minería. 
- Las familias pelean por la propiedad de las tierras.

- Las familias no llegan a un acuerdo en la redistribución de las ganancias.

Todo esto afecta las relaciones al interior de las familias, provoca pérdida de los roles y funciones dentro del núcleo familiar, permisibilidad en las acciones de los hijos, e incluso puede llegar a la violencia verbal y física, y con ello a una dinámica social hostil dentro del municipio.

\section{Impacto interfamiliar}

Por conflictos interfamiliares se entiende a aquellos sucesos que pasan dentro de dos o tres núcleos familiares, los cuales en el municipio de Lloró, según los entrevistados, también fueron dinamizados por el ejercicio de la actividad económica de la minería, que los llevó a interponer demandas o denuncias anta la Inspección de Policía.

Las principales causas fueron:

- Problemas en límites o linderos entre las familias.

- Problemas en la tenencia o propiedad de la tierra.

Estos problemas, motivados por las ganancias que deja esta actividad, que si bien "sirvió para que algunas familias cambien la fachada o aspectos de sus viviendas", causaron una laceración en las relaciones familiares.

\section{Impacto comunitario}

No todas las personas tienen conocimiento del impacto de la actividad minera en la comunidad, estos problemas son de mayor conocimiento en algunos sectores como la Iglesia, los Consejos Comunitarios (COCOILLO), funcionarios públicos como concejales, inspectores de policía, o se conocen por el medio de comunicación local, la emisora Lloró Estéreo.

Para este año, en el municipio de Lloró existían aproximadamente 10 dragones (Ayala, 2016), que provocaron dos conflictos familiares, mientras que en 2017, con solo dos dragones se desarrollaron cuatro conflictos comunitarios entre los municipios de Lloró, Bagadó y Atrato, problemas entre el corregimiento de Boraudo y la vereda de Peñalosa, así como diferencias entre Villanueva y Tapera Lloró (ver figura 4), conflictos que obedecieron específicamente a problemas de linderos entre corregimientos y veredas, y que se originan por supuestas confusiones en los límites entre las veredas y los corregimientos. Motivados igualmente por la cantidad de recursos a los que tienen derecho por ser los propietarios de los predios donde se ejerce la minería. Uno de los casos más emblemáticos es el de Boraudo con el caserío de Peñalosa (Rentería y Antonio, 2016). 


\section{Problemas de límites entre municipios}

Sus causas son las mismas que con las veredas y corregimientos pero con mayor intervención de actores institucionales y organizaciones comunitarias de los dos entes territoriales. El caso más relevante es el problema limítrofe entre el municipio del Medio Atrato y el corregimiento de Boraudo (Rentería, 2017).

Pese a que la actividad minera de cierta manera facilitó el mejoramiento de viviendas, no generó cambio en la calidad de vida de las familias y habitantes en general, al contrario ha conllevado a una serie de conflictos, no solo dentro del municipio sino que traspasa los límites con municipios vecinos, como el de Atrato y Bagadó. Todos estos problemas no han tenido el suficiente control por parte de las autoridades locales, departamentales ni nacionales, a pesar de los devastadores efectos sociales, económicos y ambientales.

Figura 4. Conflictos comunitarios.

\section{Número de casos inter e intracomunitarios}

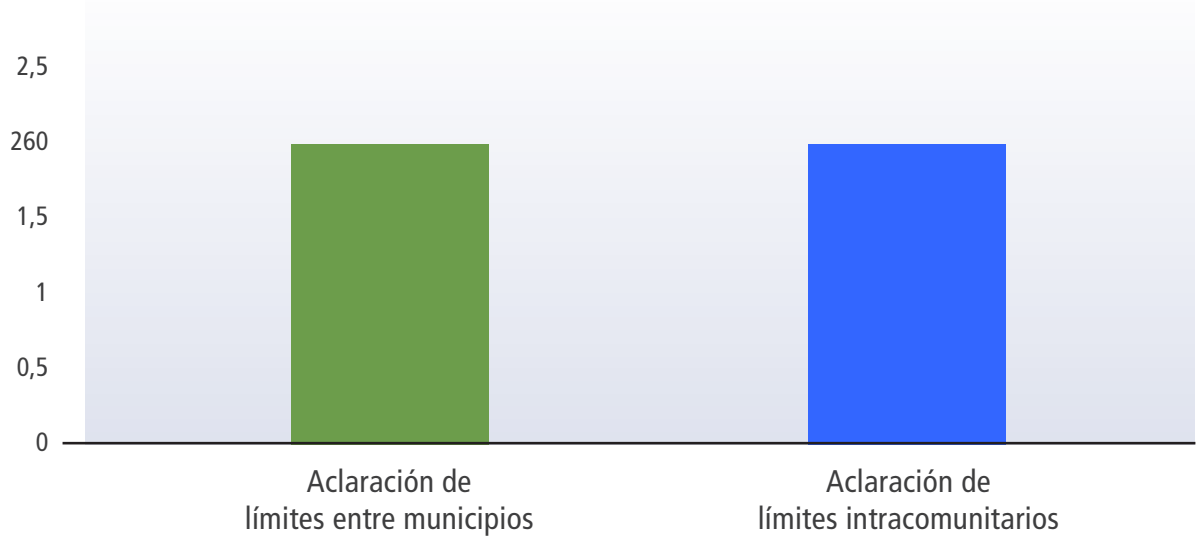

\section{Conclusiones}

Este estudio demuestra que al convertirse, la minería aurífera aluvial, en la principal actividad productiva en el municipio de Lloró a manos de foráneos nacionales y extranjeros, se generaron rupturas sociales y culturales, y se provocó un cambio sustancial en el relacionamiento de los ciudadanos del municipio, situación que se agudizó con la presencia de grupos al margen de la ley.

Para el periodo de 2008-2011, la minería artesanal en Lloró pasó de ser una actividad secundaria a convertirse en la primera actividad económica, familias que anteriormente se dedicaban a la agricultura, ahora se ocupaban en la actividad minera. Este fenómeno provocó el retorno de personas 
oriundas del municipio que se encontraban en otros departamentos y con ellos la llegada de foráneos nacionales y extranjeros. Para la fecha se creía que en el municipio había cerca de 37 retroexcavadoras (Ayala, 2016) y 70 entables mineros (Segalla, 2017), con marcada presencia de grupos guerrilleros, quienes ejercían control de esta actividad. Y es en esta fecha que inician las denuncias ante la Inspección de Policía, relacionadas con conflictos por la propiedad de territorios entre familias y personas de la comunidad (Ramos, 2016).

Durante el periodo de 2012 a 2015, aumentan las extorsiones por parte de grupos guerrilleros y los atracos por la delincuencia común. Los entables mineros bajan aproximadamente a 25 retroexcavadoras (Ayala, 2016) y la violencia y el conflicto aumentan significativamente en el municipio. Porque en el corregimiento de Boraudo se instalaron bandas criminales y post paramilitares sin ningún control por parte de las autoridades, quienes no solo llegaron a controlar los entables mineros mediante el cobro de extorciones, sino que ejercieron acciones violentas hacia la comunidad, como el cobro de vacunas a comerciantes y a toda aquella persona que ellos consideraran.

El desarrollo de la actividad de la minería aurífera aluvial ilegal a manos de foráneos, junto con la presencia de grupos al margen de la ley sin control, agudizó los problemas socioculturales y familiares del municipio, lo que generó dificultades como la falta de control en las actividades de esparcimiento, es decir en cualquier día de la semana se podía hacer fiestas y escuchar música a todo volumen, la música que más sonaba eran los narcocorridos, que dejan mensajes incorrectos a la sociedad. Así mismo en la comunidad se establecieron más de ocho chongos (lugares donde se ejerce la actividad sexual o prostitución) con trabajadoras sexuales foráneas, cuyo número disminuyó a medida que se reducía la actividad minera; para el año 2016 solo quedaban dos chongos en el municipio (datos suministrados por la Inspección de Policía de Lloró, 2016). Adicionalmente muchas mujeres adolescentes y jóvenes del municipio quedaron en embarazo y posteriormente se convirtieron en madres solteras, sin respaldo económico por parte de los padres de sus hijos.

La actividad minera también ha afectado a los jóvenes del municipio, muchos de ellos aprendieron costumbres ajenas como el consumo de bebidas alcohólicas y sustancias psicoactivas como marihuana y perico. Esto los convirtió en personas agresivas y de difícil manejo en los núcleos familiares, por ser una etapa en la que se experimentan cambios significativos de la adolescencia a la juventud. Así mismo, muchos jóvenes se involucraron en actividades delictivas que se configuran alrededor de la minería, y por ende abandonaron sus actividades escolares (Cuesta, C., 2017).

De igual manera, se puso en riesgo la seguridad alimentaria por el abandono de la actividad agrícola, lo que provocó escases en los productos básicos del municipio; los animales de caza se fueron lejos por la contaminación auditiva y la tala de bosques, mientras que los ríos se contaminaron, no hubo subienda de pescado, y se rompió el proceso de intercambio cultural que se configura con el uso de los ríos. 
Por otro lado, se presentaron nueve homicidios de personas que ejercían esta actividad, aumentaron las extorsiones a los entables mineros y a los comerciantes, hubo intimidación a la comunidad y sus líderes; situación que provocó un cambio en las costumbres de relacionamiento entre los habitantes del municipio, la comunidad se vio obligada a cambiar sus hábitos, por ejemplo comenzaron a cerrar sus viviendas más temprano, y disminuyó la participación en las actividades comunitarias por el miedo generalizado.

Los principales conflictos intrafamiliares a raíz de la minería obedecen a que las familias no llegan a un acuerdo por alquilar o vender el terreno para el ejercicio de la minería, o tienen dificultades en la redistribución de las ganancias, diferencias que escalan de la violencia verbal a la violencia física, y como última opción acude a la Inspección de la Policía a interponer las denuncias. En cuanto a los conflictos interfamiliares el tema principal son los límites o linderos entre el uno y el otro, y la tenencia de la propiedad. En lo comunitario también obedece a temas de linderos entre corregimientos, veredas y hasta problemas de límites entre municipios.

Para el periodo de 2008-2011 se contaba con la presencia de 70 entables mineros o máquinas (Segalla, 2017) que provocaron 31 conflictos familiares, para el periodo de $2012-2015$ se podían contar 25 entables mineros con 20 casos de conflictos inter e intrafamiliares. Para el año 2016 en el municipio existían aproximadamente 10 dragones con dos casos de denuncias familiares, siendo los conflictos ya no dinamizados por retroexcavadoras sino por los dragones, que para 2017 bajaron a 2 (Ayala, 2016), y que generaron 4 conflictos entre el municipio de Lloró, el municipio del Atrato y el municipio de Bagadó, problemas entre el corregimiento de Boraudo y la vereda de Peñalosa, problemas entre Villanueva y Tapera Lloró, como se denota en la figura 2.

Por último se puede concluir que la minería aurífera aluvial ilegal como nuevo actor económico a manos de foráneos nacionales y extranjeros con costumbres culturales y socioeconómicas diferentes, fue la principal causa de los conflictos socioculturales, familiares y comunitarios en el municipio de Lloró, y que se agudizó con la presencia de grupos al margen de la ley, grupos pos-paramilitares o bandas criminales que se asentaron en el corregimiento de Boraudo, situación que laceró las relaciones familiares y comunitarias hasta el día de hoy.

\section{Referencias}

Ayala, Y. (17 de diciembre de 2016). Proyecto de investigación La minería en los últimos 10 años, como dinamizadora de conflictos socioculturales en el municipio de Lloró. [Entrevista]. (S. Guerrero, entrevistador).

Conde, S. G. (2012). Minería: Maldición de los recursos o locomotora del desarrollo. El caso de la injerencia de actores armados en la minería de oro en el Chocó. Cali: Universidad Icesi. 
Cuesta, C. (13 de abril de 2017). Proyecto de investigación La minería en los últimos 10 años, como dinamizadora de conflictos socioculturales en el municipio de Lloró. [Entrevista]. (S. Guerrero, entrevistador).

Cuesta, E. (2017). Proyecto de investigación La minería en los últimos 10 años, como dinamizadora de conflictos socioculturales en el municipio de Lloró. [Entrevista]. (S. Guerrero, entrevistador).

DANE. (12 de agosto de 2016). Estimaciones de población 1985-2005 y proyecciones de población 2005-2020 total municipal por área. Bogotá: DANE. Recuperado de https://www.dane.gov.co/index.php/estadisticas-por-tema/ demografia-y-poblacion/proyecciones-de-poblacion.

Enciclopedia Británica en español. (2009). Ciudad: Editorial.

Guerrero, J. (23 de junio de 2016). Proyecto de investigación La minería en los últimos 10 años, como dinamizadora de conflictos socioculturales en el municipio de Lloró. [Entrevista]. (S. Guerrero, entrevistador).

Guerrero, M. (5 de diciembre de 2016). Proyecto de investigación La minería en los últimos 10 años, como dinamizadora de conflictos socioculturales en el municipio de Lloró. [Entrevista]. (S. Guerrero, entrevistador).

La otra Colombia. (10 de 01 de 2017). Chocó: la quimera del oro. Recuperado de http://laotracolombiac.blogspot.com.co/2010/12/choco-la-quimera-deloro.html

Manga, G. (7 de diciembre de 2015). El horror y la sangre del oro en el Chocó. Revista Semana. Recuperado de https://www.semana.com/opinion/ articulo/mineria-ilegal-en-choco-causa-danos-en-medio-ambiente-en-loshabitantes-opinion-german-manga/452703-3

Martínez, Y. (12 de agosto de 2016). Consumo de drogas en el marco del proyecto de investigación La minería en los últimos 10 años, como dinamizadora de conflictos socioculturales en el municipio de Lloró. [Entrevista]. (S. Guerrero, entrevistador).

Martínez, Y. (4 de abril de 2016). Consumo de sustancia alucinógenas en Lloró, Chocó. [Entrevista]. (S. Guerrero, entrevistador).

Moncada, L.A. (8 de marzo de 2012). Minería ilegal en Colombia, un frente de guerra que se abre. Revista Análisis Político. Universidad Militar Nueva Granada.

Palacios, A. E. (15 de diciembre de 2016). Proyecto de investigación La minería en los últimos 10 años, como dinamizadora de conflictos socioculturales en el municipio de Lloró. [Entrevista]. (S. Guerrero, entrevistador).

Palacios, H. A. (10 de marzo de 2016). Casos en inspección por actividad minera en Lloró, Chocó. [Entrevista]. (S. Guerrero, Entrevistador) Lloró.

Ramírez,J. R. (septiembre-diciembre de 2012). Huellas musicales de la violencia: el “movimiento alterado" en México. Sociológica, 27(77), pp. 181-234. 
Ramos, M. Y. (16 de diciembre de 2016). Proyecto de investigación La minería en los últimos 10 años, como dinamizadora de conflictos socioculturales en el municipio de Lloró. [Entrevista]. (S. Guerrero, entrevistador).

Rentería, S. (5 de febrero de 2017). Proyecto de investigación La minería en los últimos 10 años, como dinamizadora de conflictos socioculturales en el municipio de Lloró. [Entrevista]. (S. Guerrero, entrevistador).

Rentería, S. y Antonio, P. (12 de junio de 2016). Proyecto de investigación La minería en los últimos 10 años, como dinamizadora de conflictos socioculturales en el municipio de Lloró. [Entrevista]. (S. Guerrero, entrevistador).

Rish, E. (2005). El valor de la cultura en los procesos de desarrollo urbano sustentable. Catalunya: Generalitat de Catalunya.

Segalla, R. (10 de enero de 2017). Dinámica social y cultural por minería en Lloró. [Entrevista]. (S. Guerrero, Entrevistador)

Torres, J., Pinzón, M., Salcedo, M. Esquivia, M., Parra, A., Espitia, E. (2016). La explotación ilícita de recursos minerales en Colombia. Caso Valle del Cauca (Rio Dagua) - Chocó (Rio San Juan). Bogotá: Contraloría General de la República.

Unión de Radios Libres y Comunitarias de Madrid (URCM). (27 de noviembre de 2008). Del corrido al narcocorrido, la evolución de uno de los géneros musicales más populares de México. Recuperado de http://audio.urcm.net/ Del-corrido-al-narcocorrido-la.

Vela, A. (2015). Del concepto jurídico de familia en el marco de la jurisprudencia constitucional colombiana: un estudio comparado en América Latina. Bogotá: Universidad Católica de Colombia.

Yasno, F. (2014). Impacto medioambiental por la explotación ilegal de oro en el departamento del Chocó (Ensayo para optar por el título de Especialista en Finanzas y Administración Pública). Universidad Militar Nueva Granada, Bogotá, Colombia.

Zapata, J. (7 de agosto de 2014). Es más rentable para los ilegales explotar oro que coca. Revista Semana. Recuperado de https://www.semana.com/nacion/ articulo/la-rentabilidad-de-la-mineria-ilegal-en-colombia/397956-3 